\title{
FUNGSI TARI NYAMBAI PADA UPACARA PERKAWINAN ADAT NAYUH PADA MASYARAKAT SAIBATIN DI PESISIR BARAT LAMPUNG
}

\author{
Oleh: Cintia Restia Ningrum \\ Pembimbing Tugas Akhir: Dr. Rina Martiara, M. Hum dan Dr. Hersapandi, MS \\ Jurusan Tari, Fakultas Seni Pertunjukan, Institut Seni Indonesia Yogyakarta \\ Email: Cintiarestianingrum95@gmail.com
}

\begin{abstract}
RINGKASAN
Tari Nyambai adalah tari kelompok berpasangan yang dilakukan oleh gadis (muli) dan bujang (mekhanai) sebagai ajang pertemuan atau ajang silahturahmi untuk mencari jodoh. Sebagai tarian adat pada masyarakat saibatin (pesisir), kehadirannya menjadi bagian dari rangkaian upacara perkawinan yang disebut dengan upacara Nayuh/Penayuhan. Upacara Nayuh/Penayuhan adalah upacara perkawinan adat besar-besaran yang diadakan oleh masyarakat Lampung yang beradat Saibatin/pesisir. Metode analisisis bersifat deskriptif analisis dengan pendekatan teori fungsi dan teori sosio-budaya. Ada tiga kategori fungsi dalam kebudayaan yakni, 1). Kebudayaan harus memenuhi kebutuhan biologis, seperti kebutuhan akan pangan dan prokreasi, 2) Kebudayaan harus memenuhi kebutuhan instrumental, seperti kebutuhan akan hukum dan pendidikan, dan 3). Kebudayaan harus memenuhi kebutuhan integratif, seperti agama dan kesenian. Dalam sosiologi budaya ada tiga komponen pokok, yaitu 1). Institution atau lembaga budaya yang menanyakan: siapa yang mengontrol, dan bagaimana kontrol itu dilakukan, 2) Isi budaya menanyakan produk atau simbol apa yang dihasilkan, dan 3). Efek budaya menanyakan apa yang diusahakan. Tari Nyambai dan upacara Nayuh pada masyarakat Saibatin di Pesisir Barat Lampung mencerminkan adanya keharmoinisan komunikasi masyarakat dan bentuk peneguhan upacara pernikahan sebagai kebijakan adat yang harus dipatuhi seluruh warga pesisir Barat, Lampung sebagai basis sosialnya.
\end{abstract}

Kata kunci: Tari Nyambai, upacara Nayuh, pesisir Saibatin.

\section{ABSTRACT}

Nyambai is a pair group dance composition mekhanai (unmarried) and muli (virgin) as a site of get along or hospitality and seeking true love. As traditional dance in society of saibatin ( coastal area), the presence as the part of chain of wedding ritual of coastal society that is called as 
Nayuh/Penayuhan ceremony. Nayuh/Penayuhan ceremony is an enormous wedding ritual which is hold by Lampung society which has saibatin/coastal tradition. The analysis method is analysis descriptive with function and sosio-culture theoris as approachment. There are there levels of function on culture, they are: 1) Culture must fulfill the need of biologist, as the needs of eating and procreation, 2) Culture must fulfill the need of instrumental, as the needs of law and education, and 3) Culture must fulfill the need of integrative, such as religion and art. Within culture sosiology there are there main components, they are 1) institutution or culture institution that questioning: who is controller, and how the control is done ( culture institution), 2) Culture contain, is product or symbol that will be produced ( Nyambai dance), and 3) Culture Effect, is what is worked for. Elaboration between fungtion and sosio-cultural that reflect or harmony of societal communication and the form of Wedding ritual as the policy of culture that must be obeyed to all coastal society of west Lampung as basic social.

Key words: Nyambai dance, Nayuh ceremony, Saibatin pesisir.

\section{PENDAHULUAN}

Tari Nyambai adalah tarian adat masyarakat Saibatin yang telah dikenal sejak lama. Tari ini merupakan satu rangkaian dengan upacara perkawinan adat Nayuh yang ada pada masyarakat saibatin (pesisir). Upacara adat Nayuh adalah upacara perkawinan besar-besaran seorang saibatin, Lampung. Nayuh berasal dari bahasa Lampung Nayah yang berarti "banyak". Banyak di sini menggambarkan dengan banyaknya orang yang berkumpul bersama-sama untuk melakukan kegiatan adat yang sudah ditetapkan oleh pimpinan Hadat masyarakat saibatin (wawancara dengan Sultan Baginda Ratu Riyanda Parsiasyah, 26 juli 2016). Pada pelaksanaan upacara adat Nayuh hingga puncak acara tari Nyambai, seluruh anggota masyarakat saibatin mempunyai tugas dan kewajiban masing-masing dari remaja hingga orang tua. semua mempunyai peranannya masing-masing dalam rangkaian upacara adat Nayuh tersebut.

Pada masyarakat saibatin pemimpin Hadat tertinggilah yang berhak melaksanakan upacara Nayuh dengan memakai atribut adat paling lengkap. Pada saat upacara Nayuh berlangsung, maka seluruh masyarakat yang beradat saibatin di bawah sistem kepemimpinan saibatin tersebut diharuskan untuk menurunkan wakilnya di adat, yaitu anak-anak gadis (muli) dan anak-anak bujang 


\section{JOGED}

ISSN: $1858-3989$
Cintia Restia Ningrum (FUNGSI TARI NYAMBAI PADA UPACARA PERKAWINAN ADAT NAYUH PADA MASYARAKAT SAIBATIN DI PESISIR BARAT LAMPUNG) (mekhanai) untuk menari Nyambai. Seorang pemimpin adat dan keturunan raja Saibatin akan melakukan upacara pengangkatan gelar/adok dalam upacara Penayuhan tersebut.

Upacara sebagai rangkaian tindakan khusus mempunyai aturan serta sarana khusus pula dalam menjalankannya, dan kadangkadang tari mengambil bagian di antara deretan aturan dan sarana yang berlaku (A.M. Hermien Kusmayati, 1990: 2). Kata Nyambai diambil dari kata Cambai. Cambai dalam bahasa Lampung berarti Sirih. Bagi masyarakat Lampung, sirih menjadi simbol keakraban yang seringkali digunakan dalam kehidupan sehari-hari dan upacara adat dengan makna berbeda-beda tergantung penempatannya (I Wayan Mustika, 2012: 10). Arti luas dari Nyambai adalah mempertemukan antara ujung dan pangkal dari julur Cambai, yang artinya adalah mengetahui semua keadatan masyarakat saibatin (wawancara dengan Batin Mahkota Jaya tenumbang, 28 januari 2017).

Tari Nyambai merupakan tarian pergaulan yang mempunyai aturan yang mengikat di dalamnya. Aturan dan tata cara dalam Penyambaian sudah diatur dan ditetapkan oleh pimpinan Hadat setempat. Aturan dan tata cara tersebut tidak boleh dilanggar oleh seluruh masyarakatnya. Tarian Nyambai hanya diadakan apabila ada upacara perkawinan adat Nayuh dan diadakan pada satu malam penuh. Nyambai dibagi menjadi dua, yaitu Nyambai adat dan Nyambai Tuan. Tari ini dijadikan salah satu sarana untuk tetap mempertahankan nilai kebangsawanan adat saibatin. Dengan demikian dapat dikatakan bahwa tari Nyambai bagi adat saibatin menunjukkan adanya sebuah prestise dan legitimasi seorang ketua adat (I Wayan Mustika, 2012: 11). Dalam sistem masyarakat Lampung beradat Saibatin, dan sistem-sistem simbol yang dihadirkan di dalam pertunjukan Nyambai, maka penelitian ini betujuan untuk mengupas fungsi Tari Nyambai dengan pendekatan teori Fungsi dari Malinowski yang dielaborasikan dengan pendekatan Budaya Raymond Williams.

Menurut Anya Peterson Royce tari sebagai salah satu unsur budaya tidak lepas dari kebudayaan masyarakat pendukungnya. Fungsi tari dapat dilihat dari konteks yang dibungkus di dalam teks pertunjukan tari (I Wayan Mustika, 2012.: 12). Seperti halnya tari Nyambai dan Penayuhan/Nayuh tidak dapat dipisahkan satu sama lain karena sudah menjadi bagian yang sangat penting dari masyarakat Saibatin. Tari Nyambai tidak akan akan pernah ada tanpa masyarakat pendukungnya yaitu masyarakat saibatin. Tarian Nyambai bukan hanya sebuah tarian adat saja namun juga merupakan acara yang ditunggu-tunggu oleh masyarakat saibatin khususnya masyarakat saibatin yang ada di 
Pesisir Barat Lampung. Oleh karena itu, tari Nyambai dan Penayuhan/Nayuh merupakan satu kesatuan sistem sosial yang terintegrasi dalam upacara adat. Tari umumnya mengambil peran penting di dalam kehidupan masyarakat. Umumnya tari memiliki fungsi-fungsi ritual dan sosial akan selalu dijaga keberlangsungannya oleh masyarakat. Dari penjelasan di atas, maka dapat dirumuskan pertanyaan utama dan menarik untuk diungkap sebagai berikut. 1) Apa fungsi tari Nyambai pada upacara perkawinan adat Nayuh?, 2) bagaimana lembaga budaya, isi budaya, dan efek budaya mempengaruhi upacara Penayuhan dan tari Nyambai di masyarakat saibatin di Pesisir Barat Lampung? Dari pokok permasalahan tersebut diharapkan mendapat kan temuan-temuan tentang objek penelitian, sehingga mampu menjabarkan hasil penelitian dengan baik. Pendekatan yang digunakan dalam penelitian ini diharapkan dapat menjelaskan fenomena tari dalam kehidupan masyarakat pendukungnya.

Menurut Malinowski, ada tiga tingkatan fungsi dalam kebudayaan yakni, 1). Kebudayaan harus memenuhi kebutuhan biologis, seperti kebutuhan akan pangan dan prokreasi, 2) Kebudayaan harus memenuhi kebutuhan instrumental, seperti kebutuhan akan hukum danpendidikan, dan 3). Kebudayaan harus memenuhi kebutuhan integratif, seperti agama dan kesenian (http://firdaus2014.blogspot.co.id/2014/04/teor i-teori-fungsional-dan struktural.html diunduh tanggal 19 September 2017 pukul 17.00 WIB). Dalam sosiologi budaya ada tiga komponen pokok, yaitu 1). Institution atau lembaga budaya yang menanyakan: siapa yang mengontrol, dan bagaimana kontrol itu dilakukan, (2) Isi budaya, yaitu produk atau simbol apa yang dihasilkan, dan 3). Efek budaya, yaitu apa yang diusahakan. Elaborasi antara fungsi dan sosio-budaya itu mencerminkan adanya keharmoinisan komunikasi masyarakat dan bentuk peneguhan upacara pernikahan sebagai kebijakan adat yang harus dipatuhi seluruh warga pesisir Lampung Barat sebagai basis sosialnya.

\section{PEMbahasan}

Masyarakat adat Saibatin memandang sebuah perkawinan sebagai sesuatu yang penting. Perkawinan dalam masyarakat Lampung tidak hanya merupakan urusan kedua orang tua dan pasangan yang akan menikah saja, melainkan seluruh kekerabatan dan kepenyimbangan kedua belah pihak. Bahkan, segala keputusan bukan lah menjadi hak orang tua mempelai, melainkan menjadi hak kepenyimbangan keluarga tersebut (Rina Martiara, 2014:111). Perkawinan merupakan siklus hidup manusia yang menjadi kebutuhan manusia sendiri. Kebutuhan tersebut untuk memenuhi kebutuhan seksual yaitu untuk 


\section{JOGED}

ISSN: $1858-3989$ mendapatkan keturunan. Kebutuhan tersebut menurut Malinowski adalah kebutuhan biologis. Kebutuhan biologis yang diterapkan oleh masyarakat adat saibatin dengan menggunakan upacara perkawinan adat Nayuh. Upacara adat Nayuh adalah sistem pernikahan adat saibatin diatur dengan aturan adat yang ditetapkan oleh pimpinan hadat sebagai lembaga yang mengontrol dari suatu kegiatan adat. Perkawinan adat Nayuh adalah perkawinan yang mempunyai tata aturan yang lengkap atau perkawinan besar-besaran yang dimiliki masyarakat Saibatin. Untuk keturunan raja masyarakat saibatin, upacara perkawinan adat Nayuh sebagai tempat pemberian gelar/adok, sebagai penerus dari jabatan adat yang dimiliki dari garis keturunan ayah.

Aturan dan tata cara yang ditetapkan oleh pimpinan hadat sebagai lembaga budaya untuk mengontrol kebudayaan, merupakan suatu kebutuhan instrumental dari suatu sistem keadatan dari suatu masyarakat penyangganya. Tata aturan yang berlaku dari awal upacara Penayuhan hingga puncak acaranya yaitu Penyambaian. Tata aturan untuk upacara Penayuhan adalah pembagian tugas dan tanggung jawab masing-masing, sesuai dengan kategori usia dan jabatan di dalam adat. Kategorinya mulai dari remaja (muli mekhanai), dewasa (bapak-bapak dan ibu-ibu), dan orang tua (tetua) serta raja-raja dan pimpinan hadat. Untuk pelaksana biasanya dilakukan oleh muli mekhanai dibantu oleh para kalangan dewasa, sedangkan untuk tetua dan raja-raja mengawasi serta bertanggung jawab atas seluruh kegiatan yang dilaksanakan.

Tari Nyambai adalah tarian adat masyarakat saibatin yang sudah ada sejak zaman dahulu. Tari Nyambai merupakan isi budaya dari masyarakat saibatin di Pesisir Barat, Lampung. Sebagai isi budaya, Tari Nyambai merupakan kesenian yang berbentuk pertunjukan seni tari yang ditarikan oleh muli (gadis) dan mekhanai (bujang), yang mempunyai tata aturan yang mengikat di dalamnya. Fungsi tari Nyambai di dalam masyarakat saibatin adalah kebutuhan integratif, dikarenakan masyarakat saibatin menganggap tari Nyambai bukan hanya tarian adat semata, melainkan juga merupakan hiburan untuk seluruh masyarakat saibatin. Selama berlangsungnya acara Penyambaian aturan yang paling terlihat adalah adanya pemisah tempat duduk penari muli dan mekhanai. Muli dan mekhanai dilarang duduk bersebelah-sebelahan, mereka akan duduk berhadapan. Disaat menari pun muli dan mekhanai akan menari secara bergantian sesuai dengan suku cepong masing-masing. muli dan mekhanai tidak akan menari bersama-sama. Hal demikian menjadi aturan untuk mengontrol dari segi norma adat istiadat dan agama. Agama yang dianut oleh suku 
Lampung adalah agama Islam. Di dalam tari Nyambai juga terdapat kebutuhan biologis, karena di Penyambain ajang untuk muli dan mekhanai mencari jodoh dan mengenal satu sama lain yang dibenarkan oleh adat.

Tari Nyambai merupakan puncak dan sekaligus pengesah dari rangkain upacara perkawinan adat Nayuh. dikatakan puncak karena tari Nyambai diadakan setelah atau sesudah pangan, sesuai kesepakatan musyawarah (himpun). Pangan adalah acara inti dari upacara perkawinan adat Nayuh, di dalam pangan akan diadakan ijab kabul dan makan bersama seluruh masyarakat adat saibatin. sedangkan dikatakan sebagai pengesah karena tidak akan sah rangkaian upacara perkawinan adat Nayuh jika tidak mengadakan acara tari Nyambai. Sebagai dari isi budaya atau produk masyarakat adat saibatin sekaligus sebagai sebuah pertunjukan, maka yang akan diuraikan dari peristiwa tari Nyambai adalah: tema tari, gerak, pola lantai, rias dan busana, pelaku pertunjukan, jumlah penari, jenis kelamin penari, tempat dan waktu pertunjukan, musik dan iringan, properti tari. Kesemua ini merupakan kategori-kategori yang dipakai guna mengungkap ciri umum yang terdapat di dalam gaya tari Lampung yang membedakannya dengan gaya tari dari masyarakat lain (Rina Martiara, 2014: 134).

1. Tema tari
Di dalam buku Kamus Besar Bahasa Indonesia mentakan bahwa yang dimaksud "tema" berarti ialah pokok pikiran; dasar cerita, sebagai dasar mengarang (1999: 204). Sebagai salah satu seni pertunjukan yaitu seni tari, tema umum dari tari Nyambai adalah pergaulan. Tema pergaulan dalam tari Nyambai bukan hanya mempunyai arti yang sempit, yang hanya untuk pergaulan oleh muli mekhanai nya saja tetapi juga seluruh masyarakat pendukungnya. Hal itu dikarenakan tari Nyambai adalah tarian adat masyarakat saibatin. Tari Nyambai juga menjadi identitas masyarakat saibatin sehingga eksistensi tari Nyambai masih bertahan hingga kini. Persoalan eksistensi, peran, dan fungsi tari dalam kehidupan manusia lebih berkait dengan dinamika perkembangan, pasang surut sesuai dengan dinamika kehidupan masyarakat penyangganya. Gerak

Tari pada hakikatnya merupakan susunan gerak yang telah mengalami proses penggarapan. Penggarapan gerak tari lazim disebut stilisasi atau distorsi (Hersapandi 1986: 123). Gerakan tari Nyambai adalah gerakan sederhana yang sudah mengalami stilisasi atau distorsi sesuai dengan motif gerak bujang dan gadis. Contohnya adalah gerakan membela diri atau silat/silek dari Penyambaian bujang yang sudah distilisasi sehingga menyimbolkan ketangguhan. Ketika 


\section{JOGED}

ISSN: $1858-3989$
Cintia Restia Ningrum (FUNGSI TARI NYAMBAI PADA UPACARA PERKAWINAN ADAT NAYUH PADA MASYARAKAT SAIBATIN DI PESISIR BARAT LAMPUNG)
Penyambaian muli dan mekhanai akan menari secara bergantian sesuai dengan giliran cepong (kelompok) masing-masing. Gerak dari penari laki-laki kebanyakan lebih luas dari penari perempuan yang lebih dominan lembut berbeda dengan gerak laki-laki yang lebih dominan gerakan silat atau siilek. Motif gerak adalah merupakan kesatuan dari unsurunsur gerak, sedang unsur gerak adalah kesatuan bentuk gerak yang paling sederhana. motif gerak biasanya merupakan gerak pokok (Theresia Suharti Sudarsono dalam Hersapandi, 2015: 51). Berikut motif gerak bujang dan gadis. Meliputi, motif untuk bujang (mekhanai) yaitu: Bukak Tari, Bekelai Mejong, Kakalayang 1, Sasayak, Kakalayang 2, Belah Kacang, Buwang Sawuh, Langkah Silek, Kekalayang 3, Sesayak 2, Kekalayang Akhir, Sembah.

Sedangkan motif pada gadis (muli) yaitu: Bukak Tari, Mejong Umbak Gemulung, Mejong Sasayak, Bukak Tari, Cecok Umbak Gemulung, Cecok Sasayak, Bukak Tari (Wawancara dengan Haidar Munir, tanggal 2 Februari 2017).

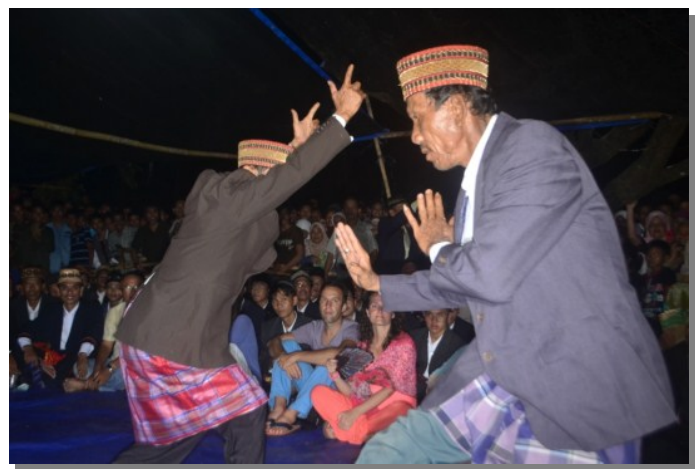

Gambar 1. Gerakan silek/silat simbol kegagahan mekahanai ( foto: dokumentasi pribadi perkawinan raja Tenumbang, 2015 )

2. Pola Lantai

Pola lantai (floor design) yang digunakan dalam tarian Nyambai adalah pola lantai sederhana. Dikatakan sederhana karena pelaku tari Nyambai adalah muli mekhanai yang bukan sebagai penari profesional. Dengan pola lantai sederhana tersebut diharapkan mampu membuat muli mekhanai tidak mengalami kesulitan dalam melakukan tariannya. Pola lantai yang dominan digunakan dalam tarian Nyambai baik untuk muli maupun mekhanai adalah pola lantai berhadapan dan diagonal sudut. Walaupun pola lantai tari Nyambai adalah brhadapan dan diagonal sudut, tetapi ada perbedaan dalam melakukan tariannya. Perbedaan tersebut terletak dari volume gerakan, level, serta keruangannya antara Penyambaian muli dan mekhanai. Untuk pola lantai muli lebih dominan dengan posisi berhadapan satu sama lain yang dilakukan dengan bergerak di tempat (stationary). Gerakan untuk laki-laki menggunakan posisi berhadapan dan diagonal serta bergerak dengan berpindah tempat (locomotor movement atau locomotion), bergerak di tempat (stationary), dan dalam posisi diam berhenti sejenak di tempat (pause). Keruangan dari Penyambaian bujang (mekhanai) memang lebih luas dibandigkan dengan keruangan gadis (muli). 


\section{Rias dan Busana}

Rias dan busana digunakan untuk menunjang penampilan suatu pertunjukan. Rias dan busana juga disesuaikan dengan jenis dan tema sebuah pertunjukan. Rias dan busana yang digunakan dalam tarian Nyambai adalah rias dan busana sederhana. Rias yang digunakan adalah rias korektif atau rias cantik. Umumnya tata rias tari tradisional sederhana, baik desain rias maupun bahan pewarna rias yang diambil dari unsur-unsur alami (Hersapandi 2015: 68). Busana yang digunakan adalah busana resmi atau busana formal, seperti menggunkan kebaya dan jas. Pakain atau busana yang digunakan oleh penari bujang (mekhanai) adalah: kain tapis atau sarung gantung, kopiah, Celana Panjang, Dasi, Baju Jas/Baju Teluk Belanga. Busana yang digunakan gadis (muli) yaitu, Kebaya/ atau Baju Kurung, Selendang, Kain Tapis Jung Sarat/ Kain Panjang, Kalung papan jajar/ Kalung Silang, Sanggul yang dihiasi kembang goyang atau pun perhiasan kepala yang lain.

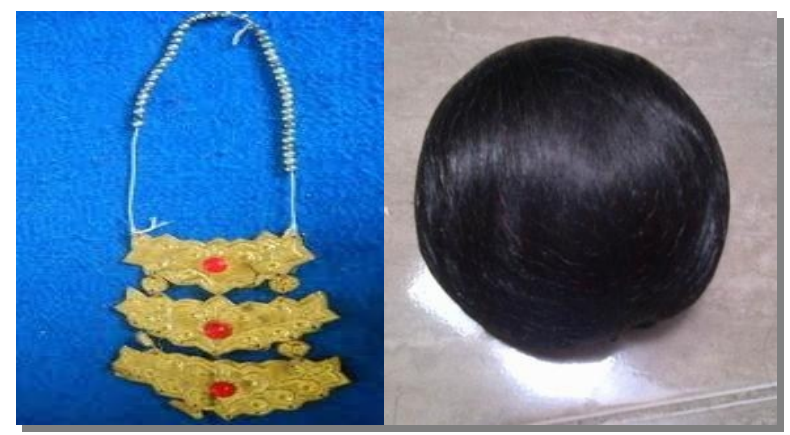

Gambar 3: Kalung Papan Jajar (kiri) dan sanggul Malang (kanan) (Foto : dokumentasi Cintia, 2017)

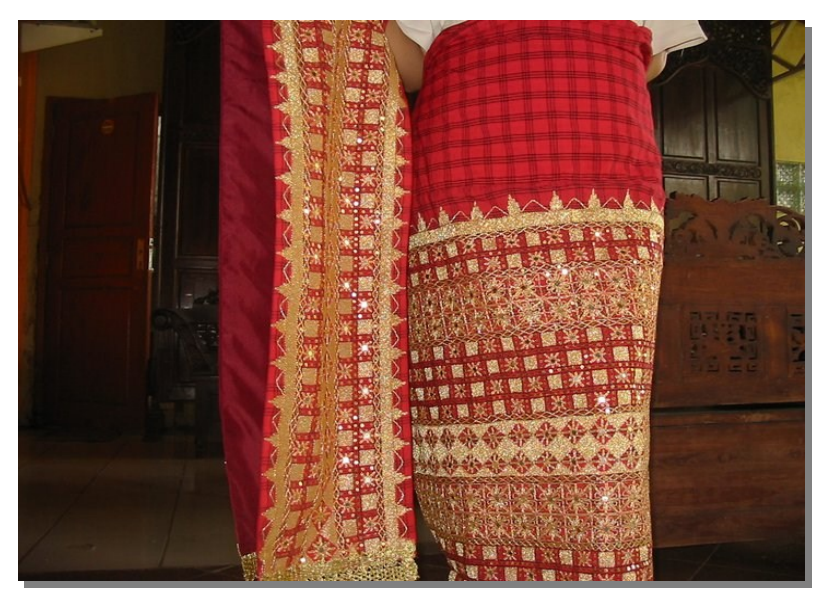

Gambar 4: kain tapis khas Lampung ( foto : dokumentasi Cintia, 2017)

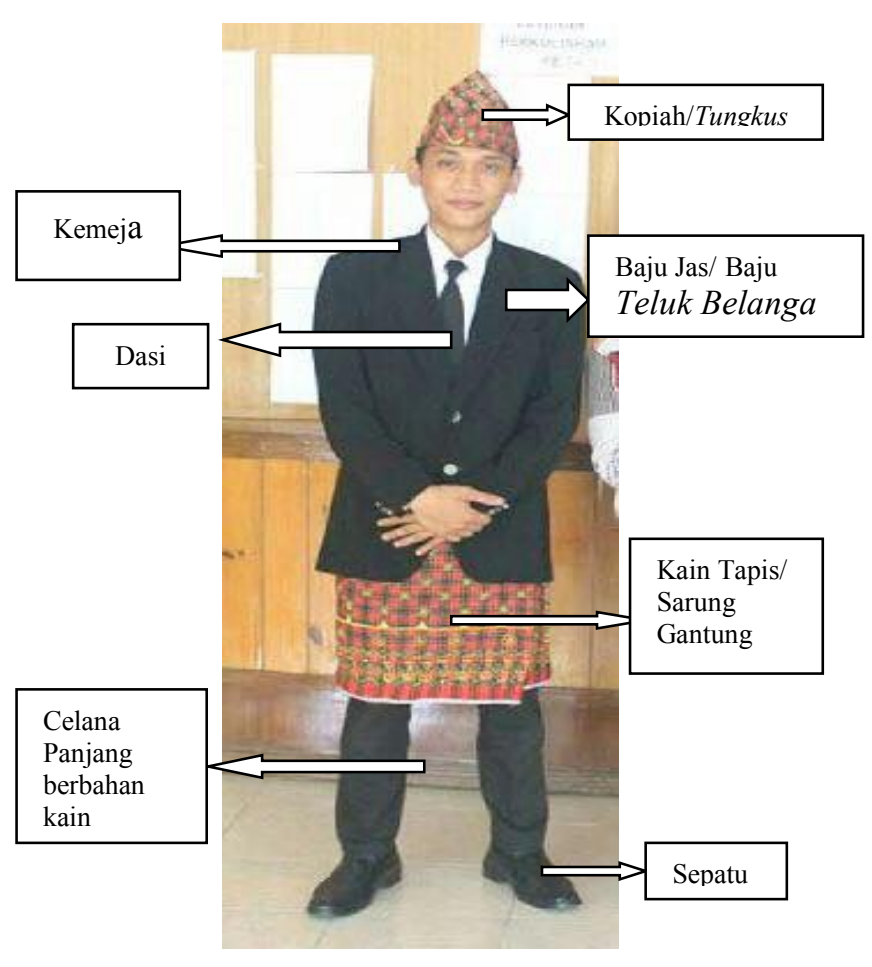

5. Pelaku Pertunjukan

Pelaku adalah orang yang terlibat di dalam sebuah pertunjukan (Rina Martiara 2014: 180). Pelaku pertunjukan paling penting dalam tari Nyambai adalah muli (gadis) dan mekahanai (bujang). Karena muli dan 


\section{JOGED}

ISSN: $1858-3989$
Cintia Restia Ningrum (FUNGSI TARI NYAMBAI PADA UPACARA PERKAWINAN ADAT

NAYUH PADA MASYARAKAT SAIBATIN DI PESISIR BARAT LAMPUNG) mekhanai sebagai penari dari dari tari Nyambai. Pelaku lainnya yang terlibat langsung maupun tidak langsung dalam pertunjukan tari Nyambai yaitu terdiri dari: pengtuha muli mekhanai (bertugas sebagai membuka dan menutup dan sebagai pengatur acara Penyambaian dan pemberi sanksi bagi yang melanggar aturan Penyambaian), jenang (keamanan dalam tari nyambai di seluruh tempat acara Penymbaian), pengtuha marga (pimpinan tertinggi), pengtuha adat (yang melihat jalannya acara Penyambaian), perwakilan suku cepong adat (yang mendampingi muli dan mekhanai ketika Penyambaian), serta pimpinan Hadat saibatin setempat.

\section{Jumlah Penari}

Berdasarkan jumlah penarinya, taritarian tradisi di Indonesia disajikan dalam bentuk tari tunggal, berpasangan, maupun kelompok (Sumaryono 2011: 157). .Tari Nyambai termasuk jenis tarian kelompok yang tidak memiliki patokan jumlahnya. Jumlah tersebut tergantung dari setiap suku cepong masing-masing yang mendatangkan perwakilan muli mekahanai di Penyambaian. Jumlah penari Nyambai tidak dapat ditentukan secara pasti. Namun demikian komposisi Penyambaian biasanya adalah kelompok besar (large group compositions), yang terdiri dari 4 penari atau lebih. Tari Nyambai biasa dilakukan dengan berpasang- pasangan lebih dari dua penari pada setiap penampilan.

7. Jenis Kelamin Penari

Penentuan jenis kelamin dalam sebuah pertunjukan terutama pertunjukan tari memang sangat penting. Hal itu berkaitan dengan apa yang ingin dibuat atau dipertunjukkan. Untuk jenis kelamin penari dalam tari Nyambai dibedakan menjadi dua jenis kelamin, yaitu gadis (muli) dan bujang (mekhanai). Muli mekhanai dipilih karena tari Nyambai adalah tarian untuk hiburan pada zaman dahulu dan juga untuk penerus generasi adat-istiadat (Wawancara dengan Iskandar : 28 januari 2017 ).

8. Tempat dan Waktu Pertunjukan

Tempat yang digunakan dalam tari Nyambai adalah tarub atau tenda semi permanen. Tarub biasa dibangun oleh masyarakat saibatin untuk tempat pertemuan penting dalam masyarakat saibatin termasuk untuk pelaksanaan Penyambaian. Tempat Penyambaian biasa dibuat memanjang karena akan dipenuhi oleh muli mekhanai dan pendamping muli mekhanai. Tidak ada ketentuan khusus tentang ukuran tarub sebagai tempat Penyambaian. Hal ini lebih ditekankan pada kemampuan dari yang mempunyai hajat serta melihat kapasitas muli dan mekhanai yang akan menari tari Nyambai. Saat acara penyambaian, tarub akan 
diberi alas tempat untuk duduk, yaitu bisa tikar maupun karpet.

Waktu adalah jadwal suatu pertunjukan dilaksanakan. Tari Nyambai dilaksanakan sebelum atau sesudah acara pangan, sesuai dengan kesepakatan himpun (musyawarah) oleh para ketua adat sebelumnya. Waktu sangat penting karena akan mempengaruhi persiapan sebelumnya. Waktu acara Penyambain biasa dilakukan setelah shalat Isya dan sampai pagi setelah azan Subuh, atau satu malam penuh. Saat ini waktu tidak lagi berlangsung selama satu malam penuh, dikarenakan banyak muli dan mekhanai yang masih bersekolah. Walaupun demikian acara Penyambaian belum akan selesai jika muli dan mekhanai belum mendapatkan giliran menari.

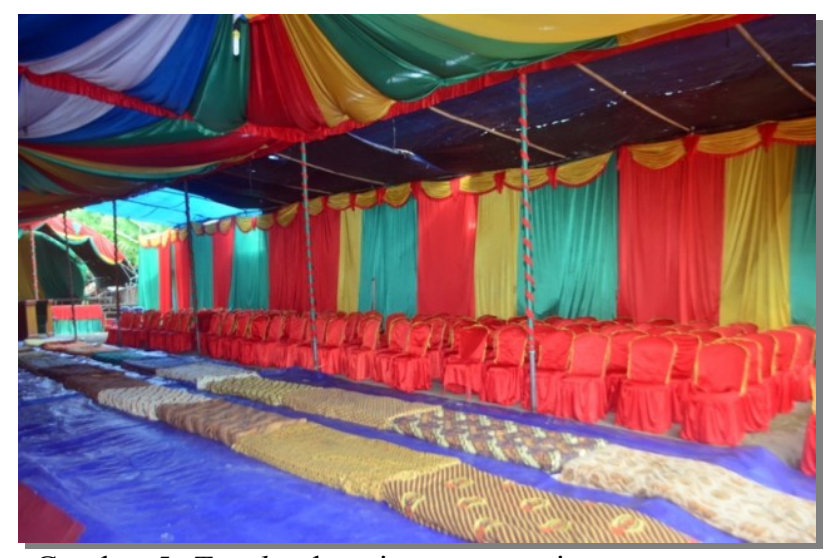

Gambar 5: Tarub sebagai tempat semi permanen yang digunakan sebagai pertunjukan tari Nyambai ( Dokumentasi: perkawinan raja Tenumbang, 2015 di Pesisir Barat Lampung )

9. Musik dan Iiringan

Iringan tari Nyambai disusun dalam pola garap komposisi musik sederhana, yaitu menggunakan instrumen khas Lampung seperti kulintang atau istilah lain seperti gulitang, klenongan, atau kemurung, serta rebana, dan gong. Musik pengiring tari di Lampung disebut dengan istilah tala balak, yang secara lengkap berjumlah 19 buah instrumen yang dimainkan oleh 9 orang penabuh (disebut penayakan). Dalam penyajiannya semua alat musik tersebut dibunyikan secara bersama-sama atau sebagian saja, sesuai dengan aturan yang ada. Hasil permainan alat musik tersebut dikenal dengan istilah tabuhan (Rina Martiara 2014: 164).

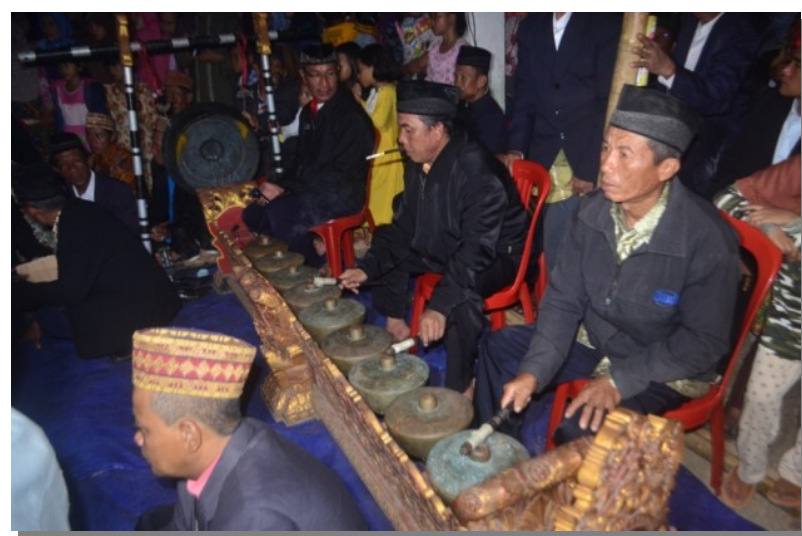

Gambar 6: Alat musik dan penabuh tari Nyambai ( Dokumentasi: perkawinan raja Tenumbang, 2015 di Pesisir Barat Lampung )

\section{Properti Tari}

Properti tari merupakan semua alat yang digunakan sebagai media atau perlengkapan dari pementasan suatu tarian. Pada dasarnya, penggunaan properti tari ditujukan untuk memberikan kesan keindahan sekaligus sebagai media untuk menyampaikan makna yang terkandung dari suatu tarian 


\section{JOGED}

ISSN: $1858-3989$ (http://sejarah-

\section{kisah.blogspot.co.id/2015/09/pengertian-}

properti-tari-dan-14-contoh.html diunduh
tanggal 27 April 2017 pukul 14.28 ). Properti yang digunakan di dalam tari Nyambai adalah kipas dan daun sirih (bulung cambai). Kipas digunakan oleh penari perempuan (muli), sedangkan properti daun sirih (bulung cambai) digunakan oleh penari bujang (mekhanai). Penggunaan properti oleh penari bujang (mekhanai) dan gadis (muli) mempunyai persamaan yaitu dipegang dikedua sela-sela jari. Properti kipas yang digunakan oleh penari muli memberikan kesan lembut dari seorang wanita, sedangkan properti bulung cambai yang digunakan oleh penari mekhanai memberikan kesan bahwa mekhanai bisa bertanggung jawab dan mengayomi keluarga serta pasangannya.

Dari uraian di atas maka kegiatan tersebut tidak dapat dilakukan oleh satu keluarga saja, melainkan melibatkan seluruh masyarakatnya, sehingga dari kegiatan tersebut masyarakat dapat saling bahu membahu dan bergotong royong untuk menyelesaikan pekerjaan adat. Masyarakat juga saling berkomunikasi satu sama lain dan bisa mengakrabkan diri dengan sesama anggota masyarakat lainnya. Hal tersebut menunjukkan bahwa dengan diadakannya upacara perkawinan adat Nayuh dan Penyambaian, menjadi ajang silaturahmi, bertambah rasa solidaritas dan rasa memiliki, menambah kekerabatan antar sesama masyarakatat saibatin, serta pencarian jodoh untuk muli dan mekhanai. Upacara perkawinan adat Nayuh termasuk ke dalam kategori tradisional. Dalam kategori tradisioanal, tampak jelas norma solidaritas dan partisipasi sebagai ideologi. Di sini ditemukan bahwa cita-cita egalitarian dan kebersamaan diwujudkan dalam kegiatan masyarakat Saibatin pesisir Barat Lampung.

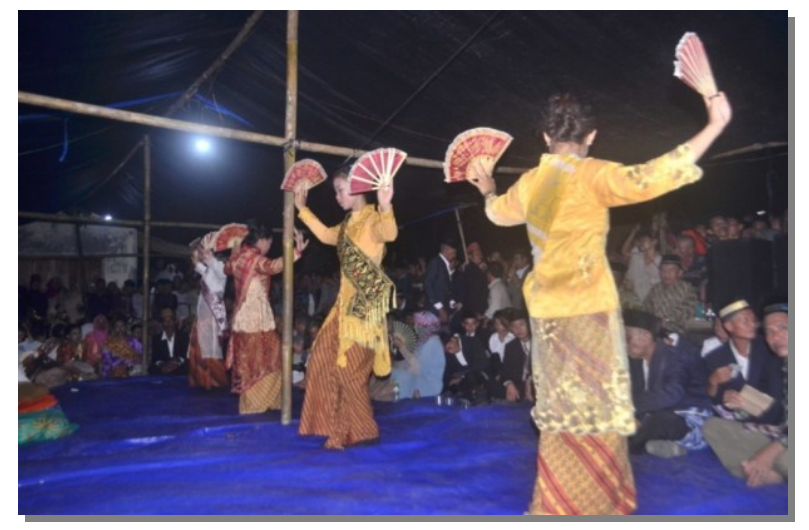

Gambar 7: Properti kipas yang digunakan sebagai tari Nyambai ( Dokumentasi: Perkawinan raja Tenumbang, 2015 di Pesisir Barat Lampung) 


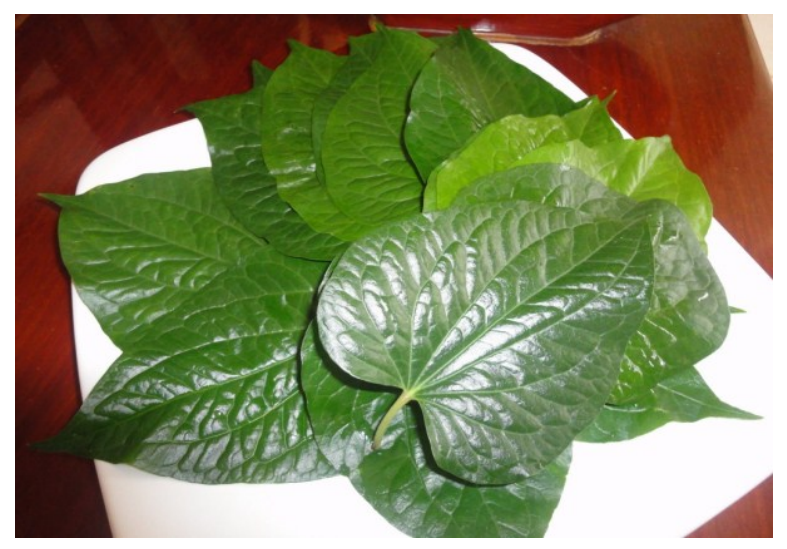

Gambar 8. Daun sirih/cambai sebagai properti mekhanai (Foto : Cintia Restia Ningrum , 2017 di Yogyakarta)

\section{PENUTUP}

Tari Nyambai adalah tarian adat yang sudah ada sejak zaman dahulu dan masih tetap dipertahankan hingga saat ini. sebagai tarian adat, Fungsi yang pertama dari tari Nyambai adalah sebagai ajang silaturahmi dan solidaritas masyarakat adat saibatin. Fungsi kedua adalah ajang keakraban dan pencarian jodoh antar muli dan mekhanai. Fungsi ketiga sebagai prestise dan legitimasi seorang pemimpin hadat. Fungsi keempat adalah sebagai media salam perpisahan dari pengantin kepada muli dan mekhanai atau pada temanteman bermain bahwasanya ia akan meninggalkan masa remajanya dan akan menjadi istri atau suami serta tugasnya di dalam adat akan berganti. Hal-hal tersebut lah yang menjadikan tari Nyambai bukan hanya sekedar tarian adat, tetapi juga sebagai sesuatu yang tidak dapat dipisahkan dari upacara perkawinan adat Nayuh.

Sebagai tarian adat yang menjadi bagian dari rangkain upacara perkawinan adat Nayuh, maka dengan memakai teori Budaya Raymond Williams, dapat disimpulkan bahwa tari Nyambai adalah hasil dari produk budaya dari masyarakat saibatin sebagai sebuah pertunjukan di dalam rangkaian upacara perkawinan adat Nayuh. Sebagai tarian adat sekaligus sebagai sebuah seni pertunjukan, maka tari Nyambai akan dikontrol oleh pimpinan hadat serta masyarakat saibatin pada umumnya. Sebagai pemegang penuh atas kontrol Penyambaian, kontrol yang dilakukan atau diterapkan oleh pimpinan hadat adalah dengan memberlakukan tata cara dan aturan yang mengikat di dalam acara Penyambaian. Tata cara dan aturan tersebut akan dipatuhi oleh pelaku tari Nyambai yaitu muli mekhanai pada khususnya dan seluruh masyarakat adat 


\section{JOGED}

ISSN: $1858-3989$
Cintia Restia Ningrum (FUNGSI TARI NYAMBAI PADA UPACARA PERKAWINAN ADAT NAYUH PADA MASYARAKAT SAIBATIN DI PESISIR BARAT LAMPUNG) saibatin pada umumnya. Tata cara dan aturan digunakan untuk mengkondisikan acara Penyambaian dari awal hingga akhir acaranya.

Isi budaya adalah menanyakan apa yang dihasilkan atau simbol-simbol apa yang diusahakan. Dari penjelasan yang dipaparkan tersebut, bisa dipahami bahwa di dalam Penyambaian dan Penayuhan juga terdapat simbol-simbol yang menyertai keseluruhan kegiatannya. Simbol-simbol yang ingin diperlihatkan di dalam Penyambaian dan Penayuhan adalah kekuasaan raja atau piminan hadat saibatin. Raja atau pimpinan hadat sangat berpengaruh di dalam kegiatan tari Nyambai atau Penyambaian dan Penayuhan. Kekuasaan raja terlihat dari perlakuan khusus bagi kalangan raja terutama bagi muli dan mekhanai ketika di acara Penyambain. Masyarakat saibatin tidak akan keberatan untuk melakukan hal tersebut dikarenakan masyarakat saibatin akan patuh serta sangat menghormati ketetapan raja atau pimpinan hadat yang sudah ada sejak dahulu. Selain dari simbol kekuasaan raja yang menyertai acara Penayuhan dan Penyambaian, simbol juga terdapat pada bentuk penyajian tari Nyambai. Simbol yang sangat terlihat adalah dari gerakan yang dilakukan oleh penari. Gerakan yang dilakukan oleh penari mekhanai yang seperti silat/silek menyimbolkan kegagahan, kewibawaan, sebagai figur pemimpin bagi kaum laki-laki, sedangkan untuk gerakan penari muli adalah lembut dan perlahan menyimbolkan kelembutan, kasih sayang, serta kehormatan seorang wanita.

Efek budaya adalah menanyakan konsekuensi apa yang diharapkan dari proses budaya itu. Upacara perkawinan adat Nayuh dan Penyambain merupakan tempat atau wadah bagi masyarakat adat saibatin untuk bekerjasama dan bergotong royong. Hal itu dikarenakan sebuah upacara perkawinan apalagi perkawinan Nayuh (perkawinan adat besar) sangatlah penting. Karena dari upacara perkawinan semua sistem keadatan berlaku dan dijalankan. Konsekuensi yang sangat terlihat dari upacara perkawinan adat Nayuh 
dan Penyambaian yang melibatkan banyak orang adalah adanya rasa solidaritas dan rasa memiliki antar masyarakat adat saibatin. Masyarakat adat Saibatin akan saling membantu satu sama lain sesuai dengan tugas dan tanggung jawab masing-masing sesuai dengan aturan dari pimpinan hadat. Tugas dan tanggung jawab dibagi atas kategori usia dan jabatan. Selain solidaritas dan rasa memiliki antar masyarakat Saibatin konsekuensi yang diharapkan diadakannya upacara perkawinan adat Nayuh dan Penyambain adalah untuk melestarikan kegiatan adat-istiadat, sehingga dengan diadakannya diacara perkawinan kegiatan adat-istiadat masyarakat saibatin tidak akan hilang.

\section{DAFTAR SUMBER ACUAN}

\section{A. Sumber Tercetak}

Kusmayati, A.M. Hermien. 1990. Makna Tari Dalam Upacara di Indonesia. Yogyakarta: Institut Seni Indonesia Yogyakarta.

Kuntowijoyo. 2006. Budaya dan Masyarakat. Yogyakarta: Tiara Wacana.
Sumaryono. 2011. Antropologi Tari. Yogyakarta: Institut Seni Indonesia Yogyakarta.

Martiara, Rina. 2014. Cangget: Identitas Kultural Lampung sebagai Bagian dari Keragaman Budaya Indonesia. Yogyakarta: Institut Seni Indonesia Yogyakarta.

Hersapandi. 2015. Ekspresi Seni Tradisi Rakyat Dalam Perspektif Transformasi Sosial Budaya. Yogyakarta: Institut Seni Indonesia Yogyakarta.

Mustika, I Wayan. 2012. Tari Muli Siger. Bandar Lampung: Anugrah Utama Raharja (AURA).

\section{B. Nara Sumber}

Riyanda Parsiasyah, 59 tahun, sebagai Sultan Baginda Ratu

Iskandar, 60 tahun, sebagai Batin Mahkota Jaya Tenumbang

Haidar Munir, 56 tahun, sebagai suku adat saksi Batin Marang

\section{Sumber Webtografi}

http://sejarah- kisah.blogspot.co.id/2015/09/ pengertian-properti-tari-dan-14-contoh.html diunduh tanggal 27 april 2017 pukul 14.28 WIB.

http://firdaus2014.blogspot.co.id/2014/04/teori -teori-fungsional-dan-struktural.html diunduh tanggal 19 September 2017 pukul 17.00 WIB. 